\title{
Use of Forward Genetic Screens to Identify Genes Required for RNA-Directed DNA Methylation in Arabidopsis thaliana
}

\author{
C. Eun, Z.J. Lorkovic, T. Sasaki, U. Naumann, A.J.M. Matzke, and M. Matzke \\ Gregor Mendel Institute of Molecular Plant Biology, Austrian Academy of Sciences, \\ A-1030 Vienna, Austria \\ Correspondence: marjori.matzke@gmi.oeaw.ac.at
}

\begin{abstract}
RNA-directed DNA methylation is a small RNA-mediated epigenetic modification that contributes to transcriptional silencing of transposons and repetitive sequences in plants. We have conducted several forward genetic screens to identify factors required for RNA-directed DNA methylation and transcriptional gene silencing in Arabidopsis thaliana. Here, we review the findings from these screens and report on two new mutants, $d m s 12$ and $d m s 13$, that are defective in Pol V-specific subunits NRPE5 and NRPE9b. Cumulative results from genetic screens performed in our laboratory and those of other investigators have revealed that RNA-directed DNA methylation requires a complex transcriptional machinery comprising a number of plant-specific factors, many of which were functionally uncharacterized before being implicated in this pathway. Future challenges include unraveling the detailed mechanism and full range of functions of RNA-directed DNA methylation.
\end{abstract}

RNA-directed DNA methylation (RdDM) is a small RNA-mediated epigenetic modification that is highly developed in flowering plants. Similarly to small RNA-mediated epigenetic processes in fission yeast (Volpe et al. 2002), Drosophila (Pal-Bhadra et al. 2002), and nematodes (Guang et al. 2008), RdDM relies on the core proteins of the RNA interference (RNAi) machinery-Dicer and Argonaute - to make and use small RNAs to guide sequence-specific chromatin modifications. RdDM targets primarily transposons and repeats and thus contributes to epigenetically silencing these sequences. When present in promoter regions, transposon relics and tandem repeats that are targets of RdDM can render downstream genes sensitive to transcriptional silencing by this pathway. RdDM thus has an important role in maintaining genome integrity and regulating a subset of genes in plants (Matzke et al. 2009; Law and Jacobsen 2010; He et al. 2011).

As described in more detail below, RdDM requires an elaborate transcriptional machinery that contains a number of plant-specific factors. Many of these factors have been identified in forward genetic screens performed in our laboratory and in those of other investigators. The central players in RdDM are two plant-specific RNA polymerase II (Pol II) - related RNA polymerases called Pol IV and Pol V (Haag and Pikaard 2011). Pol IV is needed to produce the small RNA trigger for methylation, whereas Pol V functions during downstream steps to facilitate de novo methylation of genomic DNA at the small-RNAtargeted site. Although questions remain concerning the detailed mechanism and full range of functions of RdDM, the elucidation of this complex pathway has already added a new chapter to epigenetic regulation in plants.

\section{RNA-DIRECTED DNA METHYLATION AND TRANSCRIPTIONAL GENE SILENCING}

Following early discoveries of homology-dependent gene silencing in plants, several authors suggested that various types of nucleic acid interactions, including those between RNA and DNA, could trigger gene silencing (Jorgensen 1990; van der Krol et al. 1990). The possibility that RNA molecules could direct methylation of homologous DNA sequences was attractive because it provided a means to target methylation to specific regions of the genome. The occurrence of RdDM was demonstrated in experiments showing that replicating viroids induced de novo methylation of cDNA copies of the viroid that were integrated into the plant genome (Wassenegger et al. 1994). Further work established that RdDM elicits methylation of cytosines in all sequence contexts ( $\mathrm{CG}, \mathrm{CHG}$, and $\mathrm{CHH}$, where $\mathrm{H}$ is $\mathrm{A}, \mathrm{T}$, or $\mathrm{C}$ ) and that methylation is largely restricted to the region of RNADNA sequence homology (Pélissier et al. 1999; Pélissier and Wassenegger 2000). Symmetric CG and CHG methylation can be preserved during DNA replication in the absence of the small RNA trigger by the maintenance methyltransferases METHYLTRANSFERASE 1 (MET1) and CHROMOMETHYLASE 3 (CMT3), respectively. In contrast, maintenance of asymmetric $\mathrm{CHH}$ methylation requires the continuous presence of the small RNA trigger and activity of the de novo methyltransferase DOMAINS REARRANGED METHYLTRANSFERASE 2 (DRM2) (Law and Jacobsen 2010).

Our group entered the field of gene silencing with a study demonstrating unidirectional silencing and methylation of a normally active transgene in the presence of a partially homologous, unlinked transgene locus in tobacco 
(Nicotiana tabacum) (Matzke et al. 1989; Matzke and Matzke 1991). The homologous DNA sequences shared by the unlinked transgene complexes comprised primarily promoter regions; hence, the resulting homology-dependent gene silencing resulted in promoter methylation and transcriptional gene silencing (TGS) (Neuhuber et al. 1994; Park et al. 1996). Because silencing ability was not acquired by a newly silenced locus, we proposed that the original "silencer" locus encoded a diffusible promoter RNA that acted in trans on homologous target promoters to induce promoter methylation and TGS (Park et al. 1996).

To test this hypothesis, we made a transgene construct designed to deliberately produce promoter RNAs by placing a nopaline synthase promoter (NOSpro) downstream from the constitutive $35 \mathrm{~S}$ promoter of cauliflower mosaic virus. This construct was introduced into tobacco plants expressing a NOSpro-driven neomycin phosphotransferase II (NTPII) transgene that conferred resistance to kanamycin. Out of nine "double transformants" containing both transgene constructs, only one displayed a kanamycin-sensitive phenotype that resulted from NOSpro methylation and silencing of the NPTII gene. When the structure of this "silencer" locus was examined, it was found to contain a spontaneously formed inverted repeat of NOSpro sequences that was transcribed to produce a nonpolyadenylated "aberrant" RNA that could potentially form a hairpin structure (Mette et al. 1999).

At about the same time, RNAi was reported in the nematode Caenorhabditis elegans (Fire et al. 1998), thus establishing double-stranded RNA (dsRNA) as the trigger for sequence-specific mRNA degradation in posttranscriptional gene silencing (PTGS). Given our finding that transcription of a NOSpro inverted repeat, which potentially generates a hairpin RNA, is associated with NOSpro methylation and TGS (Mette et al. 1999), we designed a construct to test whether NOSpro dsRNAs were indeed required for silencing in our system. For this, we assembled a construct containing a transcribed direct repeat of NOSpro sequences with one copy flanked by lox sites and transformed this into the NOSpro-NPTII target line. Silencing and methylation of the target NOSpro was only observed when the NOSpro direct repeat was converted into an inverted repeat in planta after crossing the target line with a plant expressing Cre recombinase (Mette et al. 2000). In plants displaying NOSpro methylation and silencing, both a NOSpro dsRNA and $\sim 23$-nucleotide small RNAs that were similar in size to those implicated in PTGS in plants (Hamilton and Baulcombe 1999) were detected (Mette et al. 2000).

\section{FORWARD GENETIC SCREENS IN ARABIDOPSIS TO IDENTIFY FACTORS REQUIRED FOR RDDM}

Work on tobacco allowed us to establish that promoter dsRNAs, which are further processed to small RNAs, act as the trigger of TGS and RdDM of homologous target promoters. With this information in hand, we could establish in Arabidopsis thaliana (Arabidopsis) well- defined silencing systems that could be used in forward genetic screens to identify factors required for this type of silencing. Here, we describe three TGS systems that we developed based on different promoters, review the outcomes of forward genetic screens using these systems, and reveal the identity of two new mutants retrieved in the latest screen.

The systems are all based on two components: a target locus, which contains the promoter of choice upstream of a reporter gene, and a silencer locus, which contains a transcribed inverted DNA repeat of the target promoter sequences under the control of the $35 \mathrm{~S}$ promoter. Transcription of the inverted repeat produces hairpin RNA that is processed to small RNAs that are 21, 22, and 24 nucleotides in length. Note that small RNA production in our TGS systems is independent of Pol IV pathway components because it relies on Pol II transcription of the inverted repeat of target promoter sequences. Therefore, the factors we have identified in our screens act in the Pol $\mathrm{V}$-mediated de novo methylation steps of the RdDM pathway.

\section{NOSpro System}

Because the NOSpro had proven to be susceptible to small RNA-mediated TGS and RdDM in tobacco, we initially set up a silencing system with this promoter in Arabidopsis. The two-component system comprised a target locus containing a NOSpro-NPTII gene and a silencer locus containing a NOSpro inverted repeat under the control of the $35 \mathrm{~S}$ promoter. In the presence of the silencer locus, the target NOSpro acquired dense CG and non-CG methylation and the NPTII gene was transcriptionally silenced, rendering plants sensitive to kanamycin (Aufsatz et al. 2002a).

A doubly homozygous target/silencer line was mutagenized using either transferred DNA (T-DNA) insertion mutagenesis or treatment with ethane methylsulfonate (EMS). Mutants were identified by screening M2 seedlings (the first generation when a recessive mutation can be homozygous) for kanamycin resistance, indicating loss of NOSpro-NPTII silencing. Three rts (RNA-mediated transcriptional gene silencing) complementation groups were retrieved in this screen (Table 1). RTS1 was identified as HISTONE DEACETYLASE 6 (HDA6) (Aufsatz et al. 2002b) and RTS2 corresponded to MET1 (Aufsatz et al. 2004).

In hda6 and met 1 mutants, CG and CHG methylation was reduced at the target NOSpro but the production of NOSpro small RNAs was not substantially affected, indicating that both HDA6 and MET1 acted downstream from small RNA biogenesis. Additional work has shown that HDA6 is involved in silencing not only transgenes but also transposons and ribosomal RNA genes during nucleolar dominance in hybrids (Earley et al. 2010 and references therein). As mentioned above, MET1 is a CG methyltransferase involved in maintenance methylation but it also possesses some de novo methyltransferase activity (Aufsatz et al. 2004; Zubko et al. 2012). It is likely 
Table 1. List of RdDM mutants identified in our forward genetic screens

\begin{tabular}{|c|c|c|c|}
\hline $\begin{array}{l}\text { Mutant } \\
\text { name }\end{array}$ & $\begin{array}{l}\text { Common name and AGI } \\
\text { number }\end{array}$ & $\begin{array}{l}\text { Number of } \\
\text { alleles }\end{array}$ & Description \\
\hline \multicolumn{4}{|c|}{ NOS promoter screen (RNA-mediated transcriptional silencing [RTS]) } \\
\hline RTS1 & HDA6 (At5g63110) & 2 & HISTONE DEACETYLASE6 (Aufsatz et al. 2002) \\
\hline RTS2 & MET1 (At5g49160) & 2 & $\begin{array}{l}\text { de novo and maintenance DNA (CG) methyltransferase (Aufsatz et al. } \\
\text { 2004) }\end{array}$ \\
\hline RTS3 & RTS3 (At5g26820) & 1 & $\begin{array}{l}\text { Chloroplast transporter required for kanamycin resistance (Aufsatz et al. } \\
\text { 2009) }\end{array}$ \\
\hline \multicolumn{4}{|c|}{$\alpha^{\prime}$ Promoter screen (defective in RNA-directed DNA methylation [DRD]) } \\
\hline DRD1 & DRD1 (At2g16390) & 6 & SNF2-like chromatin remodeling protein (Kanno et al. 2004) \\
\hline DRD2 & $\begin{array}{l}\text { NRPD2/NRPE2 } \\
(\text { At3g23780) }\end{array}$ & 12 & Common second largest subunit of RNA Pol IV and V (Kanno et al. 2005) \\
\hline DRD3 & NRPE1 (At2g40030) & 9 & Unique largest subunit of RNA Pol V (Kanno et al. 2005) \\
\hline \multicolumn{4}{|c|}{ Meristem enhancer screen (defective in meristem silencing [DMS]) } \\
\hline DMS1 & DRD1 (At2g16390) & 28 & SNF2-like chromatin remodeling protein (Kanno et al. 2004) \\
\hline DMS2 & $\begin{array}{l}\text { NRPD2/NRPE2 } \\
\text { (At3g23780) }\end{array}$ & 29 & Common second largest subunit of RNA Pol IV and V (Kanno et al. 2005) \\
\hline DMS3 & DMS3 (At3g49250) & 12 & $\begin{array}{l}\text { Structural maintenance of chromosomes hinge domain-containing } \\
\text { protein (Kanno et al. 2008) }\end{array}$ \\
\hline DMS4 & DMS4 (At2g30280) & 2 & IWR1 putative transcription factor (Kanno et al. 2010) \\
\hline DMS5 & NRPE1 (At2g40030) & 27 & Unique largest subunit of RNA Pol V (Kanno et al. 2005) \\
\hline DMS6 & DCL3 (At3g43920) & 2 & DICER-LIKE3 (Daxinger et al. 2009) \\
\hline DMS7 & RDM1 (At3g22680) & 6 & Plant-specific small protein with novel fold (Gao et al. 2010) \\
\hline DMS8 & DRM2 (At5g14620) & 3 & de novo DNA methyltransferase (Naumann et al. 2011) \\
\hline DMS9 & AGO6 (At2g32940) & 4 & ARGONAUTE6 (Eun et al. 2011) \\
\hline DMS10 & IDN2 (At3G48670) & 2 & dsRNA binding protein (Lorkovic et al. 2012) \\
\hline DMS11 & DMS11 (At1g19100) & 1 & MORC-homology GHKL-type ATPase (Lorkovic et al. 2012) \\
\hline DMS12 & NRPE5 (At3g57080) & 1 & Unique subunit 5 of RNA Pol V (this study) \\
\hline DMS13 & NRPE9b (At4g16265) & 1 & $\begin{array}{l}\text { Subunit } 9 \text { shared by RNA Pol II, IV, and V with Pol V-specific function } \\
\text { (this study) }\end{array}$ \\
\hline
\end{tabular}

that we retrieved $h d a 6$ and met 1 mutants because these factors are needed for establishing and/or maintaining CG methylation, which is presumed to be important for silencing the relatively CG-rich NOSpro. Consistent with the identification of HDA6 and MET1 in our forward screen, both proteins have subsequently been found through biochemical approaches to cooperate in maintaining locus-specific heterochromatin silencing (To et al. 2011; Liu et al. 2012).

The only other mutant identified in the NOSpro screen, $r t s 3$, was initially puzzling because the target NOSpro did not lose methylation in this mutant. However, an important clue about the possible nature of RTS3 was obtained when we failed to measure detectable levels of NPTII enzyme activity in rts3 seedlings that were kanamycin resistant. The lack of measurable NPTII enzyme activity and the retention of NOSpro methylation suggested that the resistant phenotype was not due to derepression of the NOSpro-NPTII target gene but instead to inefficient transport of kanamycin to its site of action, presumably an organelle with prokaryotic-like ribosomes. Indeed, RTS3, which has a chloroplast transit sequence, was found to correspond to a previously uncharacterized transporter protein related to ferroportins (Aufsatz et al. 2009). Silencing the endogenous RTS3 gene by using a hairpin construct rendered seedlings sensitive to kanamycin, thus substantiating the proposal that RTS3 was necessary for transporting the antibiotic into chloroplasts. RNAimediated silencing of RTS3 can be used to select for transformed plant cells on kanamycin-containing medium, thus avoiding the introduction of a bacterial
NPTII gene into the plant genome during production of transgenic plants (Aufsatz et al. 2009). A second group identified the same ferroportin-like transporter, which they termed MULTIPLE ANTIBIOTIC RESISTANCE (MAR1), and confirmed its chloroplast localization (Conte et al. 2009).

\section{$\alpha^{\prime}$ Promoter System}

To identify factors important for RdDM in seeds, we developed a two-component silencing system based on the $\alpha^{\prime}$ promoter, which is derived from a gene encoding the $\alpha^{\prime}$ subunit of $\beta$-conglycinin, a soybean-seed storage protein. The $\alpha^{\prime}$ promoter drives strong embryo-specific expression of reporter genes in transgenic plants (Chen et al. 1988). The target construct contained the $\alpha^{\prime}$ promoter fragment placed upstream of a GFP (green fluorescent protein) reporter gene. The silencer construct contained an inverted repeat of $\alpha^{\prime}$ promoter sequences transcribed from the $35 \mathrm{~S}$ promoter. In transgenic Arabidopsis plants containing both constructs, seeds were GFP negative and the $\alpha^{\prime}$ promoter was densely methylated at cytosines in all sequence contexts. Following EMS mutagenesis of the doubly homozygous target/silencer line, mutants were identified by screening for recovery of GFP expression in mature seeds. This screen yielded three $d r d$ (defective in RNA-directed) DNA methylation complementation groups (Table 1). In all three $d r d$ mutants, the target $\alpha^{\prime}$ promoter lost nearly all CG and non-CG methylation, but the abundance of $\alpha^{\prime}$ promoter small RNAs 
was unchanged, indicating that the mutations exerted their effect downstream from small RNA biogenesis (Kanno et al. 2004, 2005).

DRD1 is the founding member of a plant-specific subfamily of SNF2 chromatin remodeling factors (Kanno et al. 2004). These factors use the energy of ATP to displace nucleosomes and disrupt histone-DNA contacts. Additional members of this subfamily, including CLASSY 1 (CLSY1) in Arabidopsis (Smith et al. 2007) and REQUIRED TO MAINTAIN REPRESSION 1 (RMR1) in maize (Hale et al. 2007), have subsequently been identified in other forward screens for RNA-mediated silencing-defective mutants. Current information is consistent with DRD1 acting together with Pol V (Wierzbicki et al. 2008), at some loci with Pol II (Zheng et al. 2009), and with CLSY1 partnering with Pol IV (Smith et al. 2007), presumably to open chromatin during transcription by the respective polymerases. As described further below, DRD1 has been shown using biochemical assays to interact with other Pol V pathway components that were also identified in forward genetic screens.

DRD2 and DRD3 turned out to be the specialized largest and second largest subunits of Pol V (Kanno et al. 2005). Similarly to Pol II, both Pol IV and V are multisubunit enzymes that contain 12 individual subunits (Ream et al. 2009). The catalytic activity resides in the largest and second largest subunits. The second largest subunit of Pol V (NRPD2/NRPE2) is shared with Pol IV but is distinct from that of Pol II, whereas the largest subunit (NRPE1) is unique to Pol V (Ream et al. 2009). One loss-of-function mutation retrieved in our screen (D451N in $d r d 3-3$ ) affected the metal A binding site that is essential for catalysis, thus demonstrating that the catalytic activity of Pol V is required for RdDM (Kanno et al. 2005). Many of the nrpel mutations recovered in our screen produced premature stop codons that truncated all or part of the carboxy-terminal domain (CTD) of NRPE1 (Kanno et al. 2005), which contains glycine-tryptophan (WG/ GW) repeats that interact with ARGONAUTE (AGO) proteins (El-Shami et al. 2007). These mutations demonstrated the importance of the CTD of NRPE1 in RdDM. Reverse genetics screens performed in other laboratories also revealed the involvement of NRPE1 and NRPD2/NRPE2 in RdDM (Onodera et al. 2005; Pontier et al. 2005).

We initially designed the $\alpha^{\prime}$ promoter system to reveal seed-specific factors involved in RdDM. However, the genes we identified in the $\alpha^{\prime}$ promoter screen encode core constituents of the RdDM machinery and not factors that are expressed only in seeds. The nonoverlapping set of genes identified in the NOSpro and $\alpha^{\prime}$ promoter screens probably reflect differences in sequence composition of the respective promoters. As mentioned above, the NOSpro is relatively $\mathrm{CG}$ rich and hence requires factors important for maintaining CG methylation, such as HDA6 and MET1, for efficient silencing. In contrast, the $\alpha^{\prime}$ promoter contains fewer CG dinucleotides and appears to be repressed by non-CG methylation that depends on Pol V-mediated de novo methylation.

\section{Meristem Enhancer System}

To identify factors important for RdDM in a developmental context, we established a two-component silencing system based on an enhancer that drives expression of reporter genes in shoot and root apical meristem regions (SAM and RAM, respectively) (Mette et al. 2002). The enhancer was derived from an endogenous pararetrovirus present in the genome of Nicotiana tomentosiformis (Gregor et al. 2004). In the target construct, the viral enhancer fragment was placed upstream of a GFP reporter gene under the control of a minimal $35 \mathrm{~S}$ promoter. The silencer construct contained an inverted repeat of distal enhancer sequences under the control of the $35 \mathrm{~S}$ promoter. After introducing this construct into the target line, GFP expression in the SAM and RAM was abolished, and the target enhancer region acquired dense $C G$ and non-CG methylation. The doubly homozygous target/ silencer line was mutagenized with EMS and mutants screened for recovery of GFP expression in the RAM of newly germinated seedlings. Of the original $\sim 120$ mutants that survived and reproduced, we have so far identified $13 \mathrm{dms}$ (defective in meristem silencing) complementation groups (Table 1).

Some of the mutants corresponded to those identified in the $\alpha^{\prime}$ promoter screen. DMS1, DMS2, and DMS5 are the same as DRD1, NRPD2/NRPE2, and NRPE1, respectively. In addition, the $d m s$ screen retrieved other previously known factors in the RdDM pathway including DICER-LIKE 3 (DCL3/DMS6) (Daxinger et al. 2009), DRM2/DMS8 (Naumann et al. 2011), AGO6/ DMS9 (Zheng et al. 2007; Eun et al. 2011), and INVOLVED IN DE NOVO METHYLYLATION 2 (IDN2/DMS10) (Table 1) (Ausin et al. 2009; Zheng et al. 2010; Lorkovic et al. 2012). Our identification of AGO6 and not the more strongly and ubiquitously expressed AGO4 may reflect the preferential expression of AGO6 in SAM and RAM regions (Havecker et al. 2010).

\section{Novel Factors Identified in the $d m s$ Screen}

The first novel factor identified in the $d m s$ screen was DMS3, which is an unusual structural-maintenance-ofchromosomes-hinge domain-containing protein (Kanno et al. 2008). Authentic structural maintenance of chromosomes (SMC) proteins, such as those in cohesion and condensin complexes, are involved in large-scale chromatin dynamics. SMC proteins have an interesting structure characterized by a central hinge domain that allows them to form heterodimers with related copies of the molecule, flanked by two long coiled coils, ending in amino and carboxy termini that function as an ABCtype of ATPase (Dorsett and Ström 2012).

DMS3 is essentially a solo hinge region that lacks the long coiled coils and ATPase motif found in authentic SMC proteins (Kanno et al. 2008). The hinge domain of DMS3 is most similar to that of SmcHD1, which is required for $\mathrm{X}$ chromosome inactivation in mice (Blewitt et al. 2008). $X$ chromosome inactivation, like RdDM, is 
another epigenetic process that involves noncoding RNA and DNA methylation. However, unlike DMS3, SmcHD1 contains an ATPase domain of the GHKL (gyrase, HSP90, histidine kinase, MutL) type (Böhmdorfer et al. 2011). Intriguingly, another mutant identified in our screen, $d m s 11$, is impaired in a GHKL ATPase (Lorkovic et al. 2012). We thus postulated that DMS11 may provide the "missing" ATPase activity for DMS3.

Subsequent work demonstrated that DMS3 and DMS11 interact when coexpressed in bacterial cells and that DMS3 stimulates the ATPase activity of DMS11 in vitro (Lorkovic et al. 2012). These results, together with the highly correlated coexpression of DMS3 and DMS11 (http://www.bar.utoronto.ca/ntools/cgi-bin/ntools_expression_angler.cgi), support the hypothesis that DMS3 and DMS11 cooperate in the Pol V pathway. However, only modest epigenetic alterations were observed at target sequences in the dms 11 mutant (Lorkovic et al. 2012). Therefore, it is possible that DMS11, similarly to authentic SMC proteins, is involved in regulating higher-order chromatin structure. This suggestion is consistent with a previous proposal that MORC (microrchidia) proteins, which are the closest mammalian homologs of DMS11, are involved in manipulating DNA superstructure in response to epigenetic signals such as histone and DNA methylation (Iyer et al. 2008). Thus, DMS11, through its interaction with DMS3, may channel targets of Pol V-mediated
RdDM into higher-order chromatin configurations. A separate study suggested that DMS11, also termed AtMORC6, as well as another member of the same protein family, AtMORC1, may indeed perform this function in a heterochromatic context (Moissiard et al. 2012).

DMS7, identified as RNA-DIRECTED DNA METHYLATION 1 (RDM1) in an independent study, represents another novel plant-specific factor retrieved in our screen (Gao et al. 2010). Interestingly, before any functional information about RDM1 became available, the crystal structure of this protein was determined. This analysis demonstrated that RdDM has a unique structure containing a previously unknown protein fold (Allard et al. 2005). RDM1 is the only RdDM factor identified so far that has been shown to associate with DRM2 and AGO4 (Gao et al. 2010). Hence, RDM1 occupies a crucial position linking Pol V pathway components, including AGO4-bound small RNAs, with the DNA methyltransferase enzyme (Fig. 1). RDM1 was also found to interact with DMS3 and DRD1 in the so-called DDR complex, which assists Pol V transcription (Law et al. 2010). In our hands, both RDM1 and DMS3 form homodimers as well as heterodimers (Lorkovic et al. 2012 [see Fig. S4H therein]). Although the functional significance of this homodimerization is not yet clear, it appears to be important for the actions of DMS3 and RDM1 in RdDM (T Sasaki et al., unpubl.).

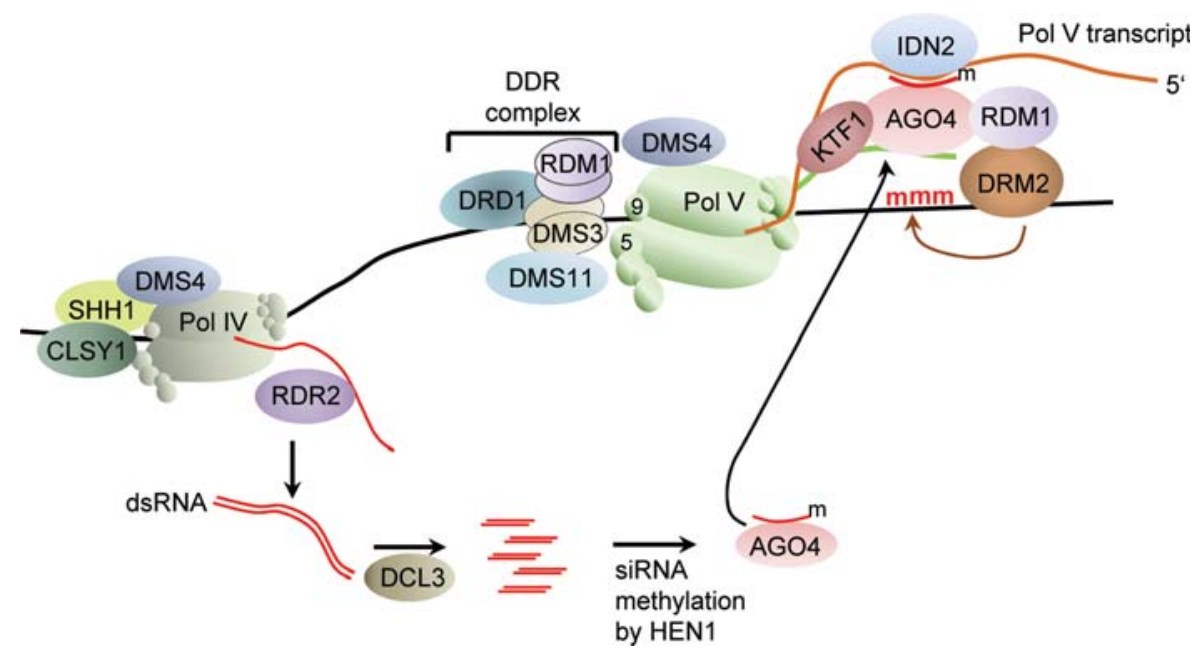

Figure 1. Model of RNA-directed DNA methylation. (Left and bottom) Pol IV-dependent biogenesis of small RNAs. A single stranded RNA (ssRNA) is transcribed at a target locus by Pol IV, which is assisted by putative chromatin remodeler CLSY1 and transcription factors SAWADEE HOMEODOMAIN HOMOLOG 1(SHH1) and DMS4. Pol IV transcripts are copied by RNADEPENDENT RNA POLYMERASE 2 (RDR2) to produce dsRNA precursors that are processed into 24-nucleotide small RNAs by DCL3. After methylation of the small RNA duplex by HUA ENHANCER 1 (HEN1), the guide strand is loaded onto AGO4-clade proteins. (Right and top) Pol V-dependent de novo methylation. Synthesis of Pol V-dependent scaffold transcripts at a target locus requires the DDR complex consisting of chromatin remodeler DRD1 as well as DMS3 and RDM1, both of which likely act as homodimers. DMS11, a GHKL ATPase with MORC homology, interacts with DMS3 and may recruit Pol V target loci into higher-order chromatin configurations downstream from de novo methylation. The largest subunit of Pol V contains a carboxy-terminal domain, which interacts with AGO4 that contains the small guide RNA. KOW TRANSCRIPTION FACTOR 1 (KTF1) also interacts with AGO4 and Pol V scaffold transcripts and likely assists AGO4 function. Base-pairing interactions between AGO4-bound small guide RNAs and Pol V scaffold transcripts are possibly stabilized by dsRNA binding protein IDN2. RDM1 coprecipitates with both AGO4 and DRM2, suggesting a means to recruit DRM2 to catalyze DNA methylation (red "m") at the small-RNA-targeted site. Whether recruitment of DRM2 requires dimerization of RDM1 and/or a functional DDR complex is not known. Two Pol V-specific subunits identified recently in our $d m s$ screen, NRPE5 and NRPE9b, are indicated by the small numbers 5 and 9 . This model is based on a model published previously by Haag and Pikaard (2011) and has been updated to include factors and data reported subsequently. 


\section{Developmental Phenotype of dms4 Mutant}

Although the $d m s$ screen was performed to identify factors important for RdDM in a developmental context, nearly all of the mutants identified in this screen do not show overt developmental phenotypes. An exception is the $d m s 4$ mutant, which is unique in displaying defects in both RdDM and plant development (Kanno et al. 2010). DMS4, identified as RDM4 in a separate screen (He et al. 2009), is an Iwr1 (interacts with RNA polymerase II)-type putative transcription factor. A global proteomics analysis in budding yeast originally identified Iwr1 as a factor that interacts with a number of subunits of Pol II (Collins et al. 2007). More recent work has suggested that yeast Iwr1 is needed for import of Pol II into the nucleus (Czeko et al. 2011) and for transcriptional initiation by Pols I, II, and III (Esberg et al. 2011). It has been proposed that the diverse effects of the dms 4 mutant in Arabidopsis are due to interactions of DMS4 with multiple polymerases. Indeed, DMS4 has been shown to interact with Pol II (He et al. 2009), Pol IV (Law et al. 2011), and Pol V (He et al. 2009). Further work is required to fully understand the contributions of DMS4 to the activities of these three polymerases.

\section{New Mutants Recently Identified in the dms Screen}

The most recent mutants we have identified are $d m s 12$ and $d m s 13$, which are defective in the specialized fifth (NRPE5) and ninth (NRPE9b) subunits, respectively, of Pol V (Table 1). As mentioned above, Pol II and the related Pol IV and V have 12 subunits, 10 of which are essential. In budding yeast, each subunit of Pol II is encoded by a single gene. But because plants have two additional polymerases, Pol IV and V, the number of genes encoding different subunits has increased accordingly (Ream et al. 2009).

The fifth subunit of Pol II is an essential subunit that interacts with transcriptional activators. Five genes encode the fifth subunit in Arabidopsis. One of these, NRPB5/NRPD5 (At3g22320), is shared by Pol II and IV (Ream et al. 2009). However, as demonstrated by reverse genetics and biochemical approaches (Huang et al. 2009; Lahmy et al. 2009; Ream et al. 2009), Pol V appears to use a distinct fifth subunit, NRPE5 (At3g57080). The fact that we have identified NRPE5 in our $d m s$ forward screen, which is revealing factors required for the Pol Vmediated steps of the RdDM pathway, substantiates the specific contribution of NRPE5 to Pol V function. The allele that we identified contains an amino acid substitution (G35D) in the amino-terminal domain. Whether this is a null mutation is unclear because methylation at the target transgene enhancer (Fig. 2) and at endogenous targets of RdDM (Fig. 3A) is only moderately reduced in the respective mutant. The remaining three genes that potentially encode a fifth subunit, referred to collectively as NRPE5-like (Ream et al. 2009), remain functionally uncharacterized.

The ninth subunit of Pol II is a nonessential subunit that nevertheless contributes in multiple ways to polymerase

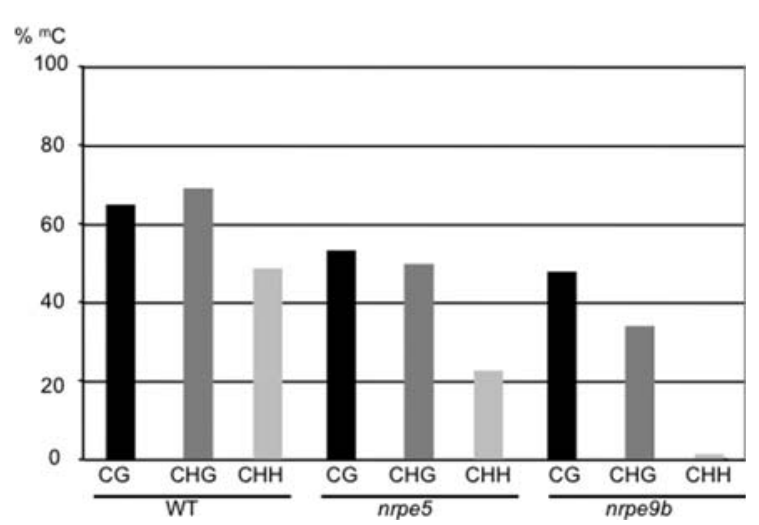

Figure 2. DNA methylation of the target transgene enhancer in nrpe 5 and nrpe $9 b$ mutants. Methylation of the target transgene enhancer was analyzed using bisulfite sequencing. The bar graph shows total methylation at cytosines in different sequence contexts in this enhancer in wild-type (WT) plants and nrpe 5 and nrpe $9 b$ mutants. $(\mathrm{CG})$ Black, $(\mathrm{CHG})$ dark gray, $(\mathrm{CHH})$ light gray.

function (Ream et al. 2009). Two genes encode the ninth subunit in Arabidopsis and initial analysis suggested that they acted redundantly in Pols II, IV, and V (Ream et al. 2009). However, a recent reverse genetics analysis indicated that NRPE9b (At4g16265) performs a Pol V-specific function in RdDM (Tan et al. 2012). This result is consistent with our identification of this gene in the $d m s$ forward genetic screen, which is picking up factors needed for Pol V-mediated steps of the RdDM pathway. The single $n r p e 9 b$ allele that we have retrieved contains a premature stop codon in the first third of the gene and is likely a null. Accordingly, the target transgene enhancer loses nearly all CHH methylation in the nrpe $9 b$ mutant (Fig. 2). Substantial loss of methylation is also observed at endogenous targets of RdDM in the nrpe $9 b$ mutant (Fig. 3A).

\section{Specializations in the "Jaw" Region of Pol V?}

In the $d m s$ screen, we identified four subunits of Pol V: the largest (NRPE1), second largest (NRPD2/NRPE2), fifth (NRPE5), and ninth (NRPE9b) (Table 1). The identification of these four subunits may reflect their positions within the multisubunit structure of Pol V. According to the crystal structure of Pol II, the largest, second largest, fifth, and ninth subunits form the so-called "jaw" region that is proposed to grip DNA during transcription (Fig. 1) (Cramer et al. 2000). Thus, our finding of these four subunits suggests that specializations in the "jaw" region of Pol V may be required to transcribe templates with certain structural or epigenetic features. However, the Pol V-dependent intergenic transcript IGN5 is still synthesized in the nrpe 5 and nrpe $9 b$ mutants that we identified (Fig. 3B). This result rather suggests that the fifth and ninth subunits may be needed to interact with regulatory components of the Pol V pathway. A similar suggestion has been made previously with respect to NRPE9b (Tan et al. 2012). 

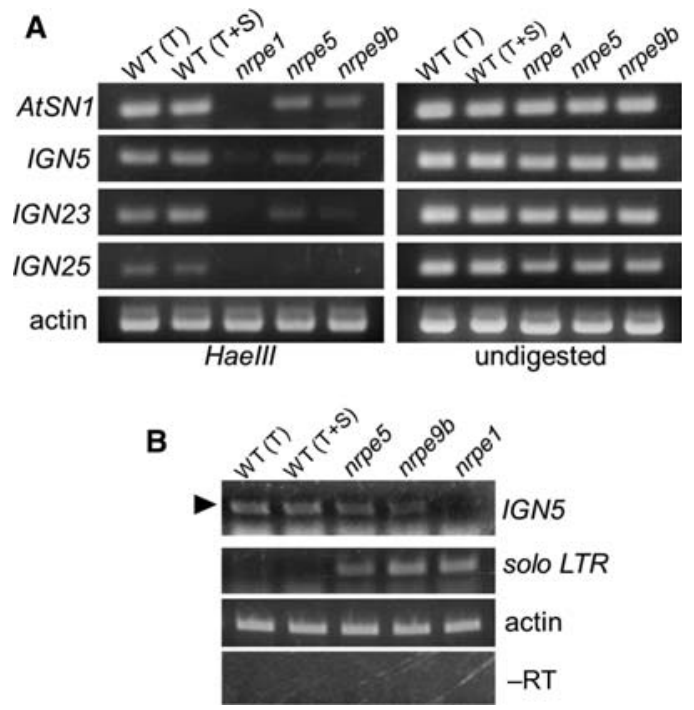

Figure 3. Methylation of RdDM targets and synthesis of Pol V transcript in nrpe 5 and nrpe $9 b$ mutants. $(A)$ Methylation of endogenous targets of RdDM (transposon AtSNI and intergenic sequences IGN5, IGN23, and IGN25) (Wierzbicki et al. 2008) was studied using the methylation-sensitive restriction enzyme HaeIII, which reports on CHH methylation, followed by polymerase chain reaction (PCR) using primers flanking the restriction site. Appearance of an amplification product is indicative of methylation. Methylation is present in WT plants containing the target transgene locus $(\mathrm{T})$ and the target and silencer transgene complexes $(\mathrm{T}+\mathrm{S})$ and is decreased in nrpe1, nrpe5, and nrpe $9 b$ mutants. Undigested controls are shown to the right. A region of the actin gene that does not contain HaeII sites (Lorkovic et al. 2012) is shown as a control for PCR amplification. (B) The intergenic transcript IGN5 (Wierzbicki et al. 2008) depends on Pol V as indicated by its loss in an nrpel mutant. In contrast, IGN5 RNA is detectable in nrpe 5 and nrpe $9 b$ mutants as well as WT plants containing the $\mathrm{T}$ and $\mathrm{T}+\mathrm{S}$ complexes. Pol II transcription of solo LTR, a target of RdDM (Huettel et al. 2006), is reactivated in mutants defective in Pol V pathway components including nprel as well as nrpe 5 and nrpe $9 b$. Actin is shown as a constitutively expressed control. (Bottom panel) Reactions minus reverse transcriptase (RT).

\section{Summary of Meristem Enhancer Screen}

The $d m s$ screen has been quite successful and is rapidly drawing to a close because only one mutant remains to be identified. Although several mutants overlapped in the $\alpha^{\prime}$ promoter and $d m s$ screens, we believe that additional unique factors were identified in the $d m s$ screen because of the increased sensitivity of GFP detection. GFP expression driven by the $\alpha^{\prime}$ promoter was somewhat difficult to discern in mature seeds, which have a brownish hue. In contrast, GFP expression was readily visualized in the RAM, which is a nearly colorless nonphotosynthetic tissue, and thus, even partial reactivation of GFP could be detected in $d m s$ mutants.

\section{CONCLUSIONS}

Forward genetic screens in our lab and and in those of other investigators as well as reverse genetic and biochemical approaches have revealed that $\mathrm{RdDM}$ requires a complex transcriptional machinery comprising a number of previously uncharacterized plant-specific factors. Additional new components continue to be discovered as genetic screens and biochemical assays become more refined. A challenge for the future is to determine how all of these specialized factors act in the mechanism of RdDM. Given that several components of the RdDM machinery-particularly in the Pol V part of the pathway - are unique to plants, it is unlikely that the RdDM mechanism will be directly comparable to that of RNAi-mediated heterochromatin formation in other organisms (Lejeune and Allshire 2011). Moreover, despite current models favoring the interaction of small RNAs with a Pol V-generated scaffold RNA (Fig. 1) (Haag and Pikaard 2011), the precise targeting of methylation to the region of RNA-DNA sequence homology argues that direct small RNA-DNA interactions create the substrate for de novo methylation. It is conceivable that some of the unusual plant-specific factors required for RdDM, such as DMS3 and RDM1, are involved in generating such hybrid nucleic acid substrates.

A second challenge is to establish the full range of functions of RdDM. Although RdDM contributes to methylation of transposons, most of these elements are not mobilized in mutants defective in RdDM (Ito et al. 2011). This contrasts to other DNA-methylation-defective mutants, such as metl and decrease in DNA methylation $1(d d m 1)$, in which many transposable elements become derepressed and capable of movement (Miura et al. 2001; Kakutani et al. 2004; Tsukahara et al. 2009). Thus, transposon silencing does not appear to be the sole function of RdDM. Clearly, plants have evolved an intricate pathway that is presumed to have important physiological roles. The recently recognized contributions of RdDM components to plant immunity (Agorio and Vera 2007; López et al. 2011) and germ line development (Van Ex et al. 2011) suggest that RdDM intertwines with pathogen defense and developmental pathways in ways that remain to be more thoroughly investigated.

\section{ACKNOWLEDGMENTS}

We thank Craig Pikaard for providing constructs for nrpe5 and nrpe $9 b$ complementation analysis. Work in the Matzke lab is supported by the Austrian Academy of Sciences and the Austrian Fonds zur Förderung der Wissenschaftliche Forschung (grant SFB F4306-B09). We also thank Johannes van der Winden for editorial assistance.

\section{REFERENCES}

Agorio A, Vera P. 2007. ARGONAUTE4 is required for resistance to Pseudomonas syringae in Arabidopsis. Plant Cell 19: 3778-3790.

Allard ST, Bingman CA, Johnson KA, Wesenberg GE, Bitto E, Jeon WB, Phillips GN. 2005. Structure at $1.6 \AA$ resolution of the protein from gene locus At3g22680 from Arabidopsis 
thaliana. Acta Crystallogr Sect F Struct Biol Cryst Commun 61: $647-650$.

Aufsatz W, Mette MF, van der Winden J, Matzke AJM, Matzke M. 2002a. RNA-directed DNA methylation in Arabidopsis. Proc Natl Acad Sci 99: 16499-16506.

Aufsatz W, Mette MF, van der Winden J, Matzke M, Matzke AJM. 2002b. HDA6, a putative histone deacetylase needed to enhance DNA methylation induced by double-stranded RNA. EMBO J 21: 6832-6841.

Aufsatz W, Mette MF, Matzke AJM, Matzke M. 2004. The role of MET1 in RNA-directed de novo and maintenance methylation of CG dinucleotides. Plant Mol Biol 54: 793-804.

Aufsatz W, Nehlin L, Voronin V, Schmidt A, Matzke AJM, Matzke M. 2009. A novel strategy for obtaining kanamycin resistance in Arabidopsis thaliana by silencing an endogenous gene encoding a putative chloroplast transporter. Biotechnol J 4: 224-229.

Ausin I, Mockler TC, Chory J, Jacobsen SE. 2009. IDN1 and IDN2 are required for de novo DNA methylation in Arabidopsis thaliana. Nat Struct Mol Biol 16: 1325-1327.

Blewitt ME, Gendrel AV, Pang Z, Sparrow DB, Whitelaw N, Craig JM, Apedaile A, Hilton DJ, Dunwoodie SL, Brockdorff $\mathrm{N}$, et al. 2008. SmcHD1, containing a structural-maintenanceof-chromosomes hinge domain, has a critical role in $\mathrm{X}$ inactivation. Nat Genet 40: 663-669.

Böhmdorfer G, Schleiffer A, Brunmeir R, Ferscha S, Nizhynska V, Kozák J, Angelis KJ, Kreil DP, Schweizer D. 2011. GMI1, a structural-maintenance-of-chromosomes-hinge domaincontaining protein, is involved in somatic homologous recombination in Arabidopsis. Plant J 67: 420-433.

Chen ZL, Schuler MA, Beachy RN. 1988. Functional analysis of regulatory elements in a plant embryo-specific gene. Proc Natl Acad Sci 83: 8560-8564.

Collins SR, Miller KM, Maas NL, Roguev A, Fillingham J, Chu CS, Schuldiner M, Gebbia M, Recht J, Shales M, et al. 2007. Functional dissection of protein complexes involved in yeast chromosome biology using a genetic interaction map. Nature 446: $806-810$.

Conte S, Stevenson D, Furner I, Lloyd A. 2009. Multiple antibiotic resistance in Arabidopsis is conferred by mutations in a chloroplast-localized transport protein. Plant Physiol 151: $559-573$.

Cramer P, Bushnel DA, Fu J, Gnatt AL, Maier-Davis B, Thompson NE, Burgess RR, Edwards AM, David PR, Kornberg RD. 2000. Architecture of RNA polymerase II and implications for the transcription mechanism. Science 288: $640-649$.

Czeko E, Seizl M, Augsberger C, Mielke T, Cramer P. 2011. Iwr1 directs RNA polymerase II nuclear import. Mol Cell 42: 261-266.

Daxinger L, Kanno T, Bucher E, van der Winden J, Naumann U, Matzke AJM, Matzke M. 2009. A stepwise pathway for biogenesis of 24-nt secondary siRNAs and spreading of DNA methylation. EMBO $J$ 28: 48-57.

Dorsett D, Ström L. 2012. The ancient and evolving roles of cohesin in gene expression and DNA repair. Curr Biol 22: R240-R250.

Earley KW, Pontvianne F, Wierzbicki AT, Blevins T, Tucker S, Costa-Nunes P, Pontes O, Pikaard CS. 2010. Mechanisms of HDA6-mediated rRNA gene silencing: Suppression of intergenic Pol II transcription and differential effects on maintenance versus siRNA-directed cytosine methylation. Genes Dev 24: 1119-1132.

El-Shami M, Pontier D, Lahmy S, Braun L, Picart C, Vega D, Hakimi MA, Jacobsen SE, Cooke R, Lagrange T. 2007. Reiterated WG/GW motifs form functionally and evolutionarily conserved ARGONAUTE-binding platforms in RNAi-related components. Genes Dev 21: 2539-2544.

Esberg A, Moqtaderi Z, Fan X, Lu J, Struhl K, Byström A. 2011. Iwr1 protein is important for preinitiation complex formation by all three nuclear RNA polymerases in Saccharomyces cerevisiae. PLoS One 6: e20829.
Eun C, Lorkovic ZJ, Naumann U, Long Q, Havecker ER, Stacey SA, Meyers BC, Matzke AJM, Matzke M. 2011. AGO6 functions in RNA-mediated transcriptional gene silencing in shoot and root meristems in Arabidopsis thaliana. PLoS One 6: e25730.

Fire A, Xu S, Montgomery MK, Kostas SA, Driver SE, Mello CC. 1998. Potent and specific genetic interference by doublestranded RNA in Caenorhabditis elegans. Nature 391: 806-811.

Gao Z, Liu HL, Daxinger L, Pontes O, He X, Qian W, Lin H, Xie M, Lorkovic ZJ, Zhang S, et al. 2010. An RNA polymerase IIand AGO4-associated protein acts in RNA-directed DNA methylation. Nature 465: 106-109.

Gregor W, Mette MF, Staginnus C, Matzke M, Matzke AJM. 2004. A distinct endogenous pararetrovirus family in Nicotiana tomentosiformis, a diploid progenitor of polyploidy tobacco. Plant Physiol 134: 1191-1199.

Guang S, Bochner F, Pavelec DM, Burkhart KB, Harding S, Lachowiec J, Kennedy S. 2008. An Argonaute transports siRNAs from the cytoplasm to the nucleus. Science 321: $537-541$.

Haag JR, Pikaard CS. 2011. Multisubunit RNA polymerases IV and V: Purveyors of non-coding RNA for plant gene silencing. Nat Rev Mol Cell Biol 12: 483-492.

Hale CJ, Stonaker JL, Gross SM, Hollick JB. 2007. A novel Snf2 protein maintains trans-generational regulatory states established by paramutation in maize. PLoS Biol 5: e275.

Hamilton AJ, Baulcombe DC. 1999. A species of small antisense RNA in posttranscriptional gene silencing in plants. Science 286: $950-952$.

Havecker ER, Wallbridge LM, Hardcastle TJ, Bush MS, Kelly KA, Dunn RM, Schwach F, Doonan JH, Baulcombe DC. 2010. The Arabidopsis RNA-directed DNA methylation Argonautes functionally diverge based on their expression and interaction with target loci. Plant Cell 22: $321-334$.

He XJ, Hsu YF, Zhu S, Liu HL, Pontes O, Zhu J, Cui X, Wang $\mathrm{CS}$, Zhu JK. 2009. A conserved transcriptional regulator is required for RNA-directed DNA methylation and plant development. Genes Dev 23: 2717-2722.

He XJ, Chen T, Zhu JK. 2011. Regulation and function of DNA methylation in plants and animals. Cell Res 21: 442465.

Huang G, Jones AM, Searle I, Patel K, Vogler H, Hubner NC, Baucombe DC. 2009. An atypical RNA polymerase involved in RNA silencing shares small subunits with RNA polymerase II. Nat Struct Mol Biol 16: 91-93.

Huettel B, Kanno T, Daxinger L, Aufsatz W, Matzke AJM, Matzke M. 2006. Endogenous targets of RNA-directed DNA methylation and Pol IV in Arabidopsis. EMBO J 25: $2828-$ 2836.

Ito H, Gaubert H, Bucher E, Mirouze M, Vaillant I, Paszkowski J. 2011. An siRNA pathway prevents transgenerational retrotransposition in plants subjected to stress. Nature 472: 115119.

Iyer LM, Abhiman S, Aravind L. 2008. MutL homologs in restriction-modification systems and the origin of eukaryotic MORC ATPases. Biol Direct 3: 8 .

Jorgensen R. 1990. Altered gene expression in plants due to trans interactions between homologous genes. Trends Biotechnol 8: $340-344$.

Kakutani T, Kato M, Kinoshita T, Miura A. 2004. Control of development and transposon movement by DNA methylation in Arabidopsis thaliana. Cold Spring Harbor Symp Quant Biol 69: $139-144$.

Kanno T, Mette MF, Kreil DP, Aufsatz W, Matzke M, Matzke AJM. 2004. Involvement of putative SNF2 chromatin remodeling protein DRD1 in RNA-directed DNA methylation. Curr Biol 14: 801-805.

Kanno T, Huettel B, Mette MF, Aufsatz W, Jaligot E, Daxinger L, Kreil DP, Matzke M, Matzke AJM. 2005. Atypical RNA polymerase subunits required for RNA-directed DNA methylation. Nat Genet 31: 761-765. 
Kanno T, Bucher E, Daxinger L, Huettel B, Bohmdorfer G. Gregor W, Kreil DP, Matzke M, Matzke AJM. 2008. A structuralmaintenance-of-chromosomes hinge-domain containing protein is required for RNA-directed DNA methylation. Nat $\mathrm{Ge}$ net 40: 670-675.

Kanno T, Bucher E, Daxinger L, Huettel B, Kreil DP, Breinig F, Lind M, Schmitt MJ, Simon SA, Ranjan Gurazada SG, et al. 2010. RNA-directed DNA methylation and plant development require an IWR1-type transcription factor. $E M B O$ Rep 11: 65-71.

Lahmy S, Pontier D, Cavel E, Vega D, El-Shami M, Kanno T, Lagrange T. 2009. PolV(PolIVb) function in RNA-directed DNA methylation requires the conserved active site and an additional plant-specific subunit. Proc Natl Acad Sci 106: 941-946.

Law JA, Jacobsen SE. 2010. Establishing, maintaining and modifying DNA methylation patterns in plants and animals. Nat Rev Genet 11: 204-220.

Law JA, Ausin I, Johnson LM, Vashisht AA, Zhu JK, Wohlschlegel JA, Jacobsen SE. 2010. A protein complex required for Polymerase V transcripts and RNA-directed DNA methylation in Arabidopsis. Curr Biol 20: 951-956.

Law JA, Vashisht AA, Wohlschlegel JA, Jacobsen SE. 2011. $\mathrm{SHH} 1$, a homeodomain protein required for DNA methylation, as well as RDR2, RDM4, and chromatin remodeling factors, associate with RNA polymerase IV. PLoS Genet 7: e1002195.

Lejeune E, Allshire RC. 2011. Common ground: Small RNA programming and chromatin modifications. Curr Opin Cell Biol 23: 258-265.

Liu X, Yu CW, Duan J, Luo M, Wang K, Tian G, Cui Y, Wu K. 2012. HDA6 directly interacts with DNA methyltransferase MET1 and maintains transposable element silencing in Arabidopsis. Plant Physiol 158: 119-129.

López A, Ramirez V, Garcia-Andrade J, Flors V, Very P. 2011. The RNA silencing enzyme RNA polymerase $\mathrm{V}$ is required for plant immunity. PLoS Genetics 7: e1002434.

Lorkovic ZJ, Naumann U, Matzke AJM, Matzke M. 2012 Involvement of a GHKL ATPase in RNA-directed DNA methylation in Arabidopsis thaliana. Curr Biol 22: 933-938.

Matzke M, Matzke AJM. 1991. Differential inactivation and methylation of a transgene in plants by two suppressor loci containing homologous sequences. Plant Mol Biol 16: $821-$ 830.

Matzke M, Primig M, Trnovsky J, Matzke AJM. 1989. Reversible methylation and inactivation of marker genes in sequentially transformed tobacco plants. EMBO J 8: $643-649$.

Matzke M, Kanno T, Daxinger L, Huettel B, Matzke AJM. 2009. RNA-mediated chromatin-based silencing in plants. Curr Opin Cell Biol 21: 367-376.

Mette MF, van der Winden J, Matzke M, Matzke AJM. 1999. Production of aberrant promoter transcripts contributes to methylation and silencing of unlinked homologous promoters in trans. EMBO J 18: 241-248.

Mette MF, Aufsatz W, van der Winden J, Matzke M, Matzke AJM. 2000. Transcriptional silencing and promoter methylation triggered by double stranded RNA. EMBO J 19: $5194-5201$

Mette MF, Kanno T, Aufsatz W, Jakowitsch J, van der Winden J, Matzke M, Matzke AJM. 2002. Endogenous viral sequences and their potential contribution to heritable virus resistance in plants. EMBO J 21: 461-469.

Miura A, Yonebayashi S, Watanabe K, Toyama T, Shimada H, Kakutani T. 2001. Mobilization of transposons by a mutation abolishing full DNA methylation in Arabidopsis. Nature 411: 212-214.

Moissiard G, Cokus SJ, Cary J, Feng S, Billi AC, Stroud H, Husmann D, Zhan Y, Lajoie BR, McCord RP, et al. 2012. MORC family ATPases required for heterochromatin condensation and gene silencing. Science 336: 1448.

Naumann U, Daxinger L, Kanno T, Eun C, Long Q, Lorkovic ZJ, Matzke M, Matzke AJM. 2011. Genetic evidence that DNA methyltransferase DRM2 has a direct catalytic role in RNAdirected DNA methylation in Arabidopsis thaliana. Genetics 187: 977-979.

Neuhuber F, Park YD, Matzke AJM, Matzke M. 1994. Susceptibility of transgene loci to homology-dependent gene silencing. Mol Gen Genet 244: 230-241.

Onodera Y, Haag JR, Ream T, Costa Nunes P, Pontes O, Pikaard CS. 2005. Plant nuclear RNA polymerase IV mediates siRNA and DNA methylation-dependent heterochromatin formation. Cell 120: 613-622.

Pal-Bhadra M, Bhadra U, Birchler JA. 2002. RNAi related mechanisms affect both transcriptional and posttranscriptional transgene silencing in Drosophila. Mol Cell 9: 315-327.

Park YD, Papp I, Moscone EA, Iglesias VA, Vaucheret H, Matzke AJM, Matzke M. 1996. Gene silencing mediated by promoter homology occurs at the level of transcription and results in meiotically heritable alterations in methylation and gene activity. Plant J 9: 183-194.

Pélissier T, Wassenegger M. 2000. A DNA target of $30 \mathrm{bp}$ is sufficient for RNA-directed DNA methylation. RNA 6: $55-65$.

Pélissier T, Thalmeir S, Kempe D, Sänger HL, Wassenegger M. 1999. Heavy de novo methylation at symmetrical and nonsymmetrical sites is a hallmark of RNA-directed DNA methylation. Nucl Acids Res 27: 1625-1634.

Pontier D, Yahubyan G, Vega D, Bulski A, Saez-Vasquez J, Hakimi MA, Lerbs-Mache S, Colot V, Lagrange T. 2005. Reinforcement of silencing at transposons and highly repeated sequences requires the concerted action of two distinct RNA polymerases IV in Arabidopsis. Genes Dev 19: 2030-2040.

Ream TS, Haag JR, Wierzbicki AT, Nicora CD, Norbeck AD, Zhu JK, Hagen G, Guilfoyle TJ, Pasa-Tolic L, Pikaard CS. 2009. Subunit compositions of the RNA-silencing enzymes Pol IV and Pol V reveal their origins as specialized forms of RNA polymerase II. Mol Cell 33: 192-203.

Smith LM, Pontes O, Searle I, Yelina N, Yousafzai FK, Herr AJ, Pikaard CS, Baulcombe DC. 2007. An SNF2 protein associated with nuclear RNA silencing and the spread of a silencing signal between cells in Arabidopsis. Plant Cell 19: 15071521.

Tan EK, Blevins T, Ream TS, Pikaard CS. 2012. Functional consequences of subunit diversity in RNA polymerases II and V. Cell Reports 1: 208-214.

To TK, Kim JM, Matsui A, Kurihara Y, Morosawa T, Ishida J, Tanaka M, Endo T, Kakutani T, Toyoda T, et al. 2011. Arabidopsis HDA6 regulates locus-directed heterochromatin silencing in cooperation with MET1. PLoS Genet 7: e1002055.

Tsukahara S, Kobayashi A, Kawabe A, Mathieu O, Miura A, Kakutani T. 2009. Bursts of retrotransposition reproduced in Arabidopsis. Nature 461: 423-426.

van der Krol AR, Mur LA, Beld M, Mol JN, Stuitje AR. 1990. Flavonoid genes in petunia: Addition of a limited number of gene copies may lead to a suppression of gene expression. Plant Cell 2: 291-299.

Van Ex F, Jacob Y, Martienssen R. 2011. Multiple roles for small RNAs during plant reproduction. Curr Opin Plant Biol 14: 588-593.

Volpe TA, Kidner C, Hall IM, Teng G, Grewal SI, Martienssen RA. 2002. Regulation of heterochromatic silencing and histone H3 lysine-9 methylation by RNAi. Science 297: $1833-$ 1837.

Wassenegger M, Heimes S, Riedel L, Sänger HL. 1994. RNAdirected de novo methylation of genomic sequences in plants. Cell 76: 567-576.

Wierzbicki AT, Haag JR, Pikaard CS. 2008. Noncoding transcription by RNA polymerases Pol IVb/Pol V mediates transcriptional silencing of overlapping and adjacent genes. Cell 135: $635-648$.

Zheng X, Zhu J, Kapoor A, Zhu JK. 2007. Role of Arabidopsis AGO6 in siRNA accumulation, DNA methylation and transcriptional gene silencing. EMBO J 26: 1691-1701. 


\section{EUN ET AL.}

Zheng B, Wang Z, Li S, Yu B, Liu JY, Chen X. 2009. Intergenic transcription by RNA polymerase II coordinates Pol IV and Pol V in siRNA-directed transcriptional gene silencing in Arabidopsis. Genes Dev 23: 2850-2860.

Zheng Z, Xing Y, He XJ, Li W, Hu Y, Yadav SK, Oh J, Zhu JK. 2010. An SGS3-like protein functions in RNA-directed DNA methylation and transcriptional gene silencing in Arabidopsis. Plant J 62: 92-99.

Zubko E, Gentry M, Kunova A, Meyer P. 2012. De novo DNA methylation activity of METHYLTRANSFERASE 1 (MET1) partially restores body methylation in Arabidopsis thaliana. Plant J 71: 1029-1037. 


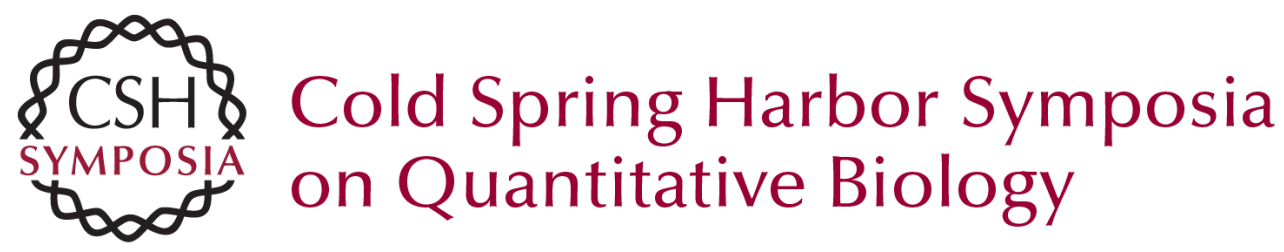

\section{Use of Forward Genetic Screens to Identify Genes Required for RNA-Directed DNA Methylation in Arabidopsis thaliana}

C. Eun, Z.J. Lorkovic, T. Sasaki, et al.

Cold Spring Harb Symp Quant Biol 2012 77: 195-204 originally published online November 28, 2012

Access the most recent version at doi:10.1101/sqb.2012.77.015099

References This article cites 78 articles, 26 of which can be accessed free at: http://symposium.cshlp.org/content/77/195.full.html\#ref-list-1

\section{License}

Email Alerting Service the box at the top right corner of the article or click here. 